\title{
SYNTHESIS OF CROWN ETHER COMPOUNDS AS POTENTIAL INHIBITORS OF ENZYMATIC DISCOLOURATION OF FOODS
}

\author{
I. SYNTHESIS OF POSSIBLE INHIBITORS \\ R. Vuković, ${ }^{\mathrm{a}}$ A. ERCEG, ${ }^{\mathrm{a}}$ V. Piližota, ${ }^{\mathrm{b}}$ and D. Šubaric $c^{\mathrm{b}}$ \\ ${ }^{a}$ INA, Research and Development Institute, HR-10000 Zagreb. Croatia \\ ${ }^{\mathrm{b}}$ Faculty of Food Technology, University of Osijek, F. Kuhača 18, HR-31000 Osijek. Croatia
}

(Received: 20 April 1998; accepted: 11 November 1998)

The synthesis of the following crown ether containing compounds as potential polyphenol oxidase inhibitors is described: 4'-N(benzo-crown-5)succinamic acid (I), 4'-N(benzo15-crown-5)malemic acid (II), ester of 4'-N(benzo-15-crown-5)bis[4'-N(benzo-15-crown5)]phthalamic acid (III) and complex of benzo-18-crown-6 with 2-propenyl-acrylamide (IV). The complexes of I, II and IV with potassium 2-propenyl-acrylamide are also described.

Keywords: complexes of crown ethers containing 2-propenyl-acrylates, inhibitors of polyphenol oxidase, synthesis of crown ether amides

The discovery of crown compounds by Pedersen during the late 1960s was followed by intensive synthesis, characterization and application of these compounds. The most important crown compounds are macrocyclic ethers, which - due to their unique properties to form complexes with metal ions - have found numerous applications in various fields, such as organic synthesis, especially polymer synthesis, analytical chemistry, capture and separation of metal ions, resolution of optical isomers and in biochemistry and biophysics (PEDERSEN, 1967a,b; 1970a,b; 1972). In a recently published review article from our Laboratory in Osijek, part of the work by Cram and co-workers concerning the application of atropisomeric crown compounds as enantioselective supports in chromatography is described (PILIŽOTA, 1998). Over one thousand scientific papers and patents related to crown compounds were published during the last few years. Recently a naturally occurring crown compound, $\beta$-cyclodextrin, has found practical use in food technology as inhibitor of enzymatic browning of fruits and vegetables (HICKS et al., 1996).

The mechanism of enzymatic discolouration of foods is described in a large number of papers and monographs (VÁMOS-VIGYÁZÓ, 1981; SAPERS, 1993; PILIŽOTA 
\& ŠUbarić, 1998). Based on extensive studies it is considered that the enzymatic browning is connected with the hydroxylation of mono-phenols to diphenols, under the subsequent oxydation of diphenols to the coloured o-quinones.

These reactions are catalysed by polyphenol oxidase which is an oligomeric metalloporphirine containing copper as prosthetic group. Based on a large number of studies it has been established that inhibitors of enzymatic discolouration, which react with copper ions, are efficient stabilizers of food products. One of these stabilizers is ascorbic acid oxidase, which also contains copper ion bound to protein (BURNs \& GREENBERG, 1963).

In view of the unusual properties of the complexing of crown compounds with metal ions, including copper ions, we have prepared several compounds which contain macrocyclic crown ethers as potential inhibitors of food discolouration caused by polyphenol oxidase. The macrocyclic ethers, which are part of the compounds described in the experimental section of this work, are benzo-15-crown-5 and benzo18-crown-6, respectively. In a recently published paper we have described the complexing ability of benzo-15-crown-5 and poly(benzo-15-crown-5-alt- $\alpha$-methylstyrene) with sodium and potassium ions, and it was found that these complexes are very stable. The sodium ion forms a 1:1 complex with benzo-15-crown-5, while potassium ions form 1:2 complexes, respectively. Both complexes are soluble in methylene dichloride (POONIA, 1974; Fleš et al., 1994).

As shown by Pedersen and Frendsdorff (1972), the stability of crown ether/metal ion complexes depends on the relative sizes of the cation and the cavity of the crown ether: the more closely they match, the more stable is the complex formed. For the crown compounds used in this work, Pedersen calculated the cavity diameters on the basis of atomic models and obtained the following values: for benzo-15-crown-5 the cavity diameter was 1.7-2.2 $\AA$ (lower values are estimated from Corey-PaulingKoltum atomic models, while higher values are calculated from Fisher-HilschfelderTaylor models). According to the data tabulated in the monography "Crown compounds, their characterization and application" by HIRAOKA (1982) the ionic diameter of $\mathrm{Cu}^{2+}$ has a value of $1.44 \AA$ and is therefore able to form stable complexes with benzo-15-crown- 5 and benzo-18-crown- 6 , respectively.

\section{Materials and methods}

\subsection{4-(Aminobenzo-15-crown-5)}

The compound was prepared by reduction of 4-(nitrobenzo-15-crown-5) following the procedure published by FLEŠ and co-workers (1992). 


\section{2. $4^{\prime}-N($ Benzo-15-crown-5) succinamic acid(I)}

A mixture of 4-(aminobenzo-15-crown-5) (0.566 g; $0.002 \mathrm{~mol})$ and $0.2 \mathrm{~g}$ $(0.002 \mathrm{~mol})$ of succinic anhydride was dissolved under heating in $4 \mathrm{ml}$ of chloroform and left overnight at room temperature. The crystalline product was removed by filtration yielding $0.41 \mathrm{~g}(53 \%)$ of product melting at $150-154{ }^{\circ} \mathrm{C}$. A sample for analysis was recrystallized from ethanol, m.p. $153-154^{\circ} \mathrm{C}$. Recrystallization from water did not change the melting point.

Analysis. Calculated for $\mathrm{C}_{18} \mathrm{H}_{25} \mathrm{NO}_{8}(383,39)$ : C, 56.39; H, 6.57; N, 3.65; Found: C, 55.89; H, 5.23; N, 3.71.

\subsection{Complex of potassium salt of 4'-N(benzo-crown-5) succinamic acid with potassium} 2-propenyl acrylamide (Ia)

4'-N(Benzo-15-crown-5)succinamic acid (0.793 g: $0.002 \mathrm{~mol})$ is dissolved in $20 \mathrm{ml}$ of $\mathrm{n}-\mathrm{KOH}$ under the addition of $0.150 \mathrm{~g}(0.001 \mathrm{~mol})$ of potassium 2-propenylacrylate. The clear filtered solution is evaporated in vacuum to dryness, yielding $1.02 \mathrm{~g}$ of white powder soluble in water.

Analysis. Calculated for $\mathrm{C}_{42} \mathrm{H}_{53} \mathrm{~N}_{2} \mathrm{O}_{18} \mathrm{~K}_{3}$ (991.2); N, 2.82; Found: N, 2.49 .

\subsection{4'-N(Benzo-15-crown-5) maleamic acid II}

Compound II was prepared according to the procedure described by FLEŠ and co-workers (1992). 4-Aminobenzo-15-crown-5 (0.566 g; $0.002 \mathrm{~mol})$ was dissolved in $4 \mathrm{ml}$ of chloroform and mixed under cooling with $0.200 \mathrm{~g}(0.002 \mathrm{~mol})$ of maleic anhydride dissolved in $4 \mathrm{ml}$ of chloroform. After standing overnight at room temperature the solvent was evaporated in vacuum, and the dark coloured crystalline product was recrystallized from water, yielding analytically pure II: Yield 95\%, m.p. $152-154^{\circ} \mathrm{C}$.

Analysis. Calculated for $\mathrm{C}_{18} \mathrm{H}_{23} \mathrm{NO}_{8}$ (381.4); C, 56.68; H, 6.08; N, 3.67; Found: C, 56.40; H, 6.10; N, 3.50.

\subsection{Complex of potassium salt of N(benzo-15-crown-5) maleamic acid with potassium}

2-propenyl acrylate (IIa)

Complex IIa was prepared in the same manner as previously described for Ia: $0.381 \mathrm{~g}, 0.001 \mathrm{~mol}$ of $\mathrm{N}$-substituted maleic acid I was dissolved in $1 \mathrm{ml}$ of $\mathrm{n}-\mathrm{KOH}$ followed by the addition of $0.075 \mathrm{~g}(0.0005 \mathrm{~mol})$ of potassium 2-propenyl-acrylate. After standing overnight at room temperature, the dark brown solution was evaporated to dryness yielding $0.41 \mathrm{~g}$ of semisolid residue which was triturated with ether; the resulting white powder was filtered off and dried in vacuum. 
Analysis. Calculated for $\mathrm{C}_{42} \mathrm{H}_{51} \mathrm{~N}_{2} \mathrm{O}_{18} \mathrm{~K}_{3}$ (989.18); C, 50.99; H, 5.20; N, 2.85; Found: C, 49.46; H, 4.27; N, 2.71.

\subsection{Ester of 4'-N(benzo-15-crown-5)-bis[4'-N(benzo-15-crown-5)]phthalamic acid (III)}

A mixture of $0.566 \mathrm{~g}(0.002 \mathrm{~mol})$ of 4-amino-benzo-15-crown-5 and $0.296 \mathrm{~g}$ $(0.002 \mathrm{~mol})$ of phthalic anhydride is heated in an oil bath at $140{ }^{\circ} \mathrm{C}$. Water and ammonia are formed under foaming and after $30 \mathrm{~min}$ a solid crystalline mass is formed. The crystalline product is dissolved in $10 \mathrm{ml}$ of chloroform, and crystallized by the addition of $10 \mathrm{ml}$ of petroleum ether (b.p. $40-70{ }^{\circ} \mathrm{C}$; yield $0.48 \mathrm{~g}, 74 \%$; m.p. $188-189^{\circ} \mathrm{C}$. A sample $(150 \mathrm{mg})$ was recrystallized from $20 \mathrm{ml}$ of isopropanol, m.p. $188-189^{\circ} \mathrm{C}$.

Analysis. Calculated for $\mathrm{C}_{50} \mathrm{H}_{61} \mathrm{NO}_{18}(963) ; 62.27 ; \mathrm{H}, 6.38 ; \mathrm{N}, 1.45$; Found: $\mathrm{C}$, $62.69 ; \mathrm{H}, 5.46 ; \mathrm{N}, 1.48$.

\subsection{Complex of benzo-18-crown-6 with 2-propenyl-acrylic acid (IVa)}

Benzo-18-crown-6 (0.312 g, $0.001 \mathrm{~mol})$ was mixed with $0.113 \mathrm{~g}(0.001 \mathrm{~mol})$ of 2-propenyl-acrylic acid and dissolved in $2 \mathrm{ml}$ of water. The residue obtained upon evaporation of water in vacuum was triturated with ether yielding $0.42 \mathrm{~g}(100 \%)$ of the title complex in the form of white powder.

Analysis. Calculated for $\mathrm{C}_{22} \mathrm{H}_{32} \mathrm{O}_{8}$ (424.5); C, 62.25; H, 7.60; Found: C, 61.93; $\mathrm{H}, 6.55$.

\subsection{Complex of benzo-18-crown-6 with potassium 2-propenyl-acrylate (IVb)}

Complex IVb was prepared in the same manner as described for IVa.

Analysis. Calculated for $\mathrm{C}_{22} \mathrm{H}_{31} \mathrm{O}_{8} \mathrm{~K}$ (462.58); C, 57.12; H, 6.76; Found: C, $56.41 ; \mathrm{H}, 7.06$.

\section{Results and discussion}

In the experimental part of this paper the preparation of the following crown ether containing compounds is described: 4'-N(benzo-15-crown-5)succinamic acid (I), 4'-N(benzo-15-crown-5)maleamic acid (II), and ester of 4'-N(benzo-15-crown-5)bis [4'-N(benzo-15-crown-5)]phthalamic acid (III). 


\section{HOOC-CH $-\mathrm{CH}_{2}-\mathrm{CONHR}$}

I

HOOC $-\mathrm{CH}=\mathrm{CH}-\mathrm{CONHR}$

II

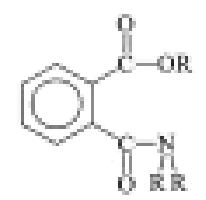

III

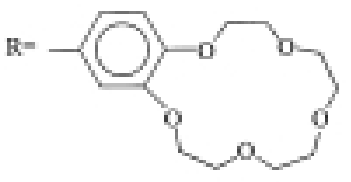

Compounds I and II are prepared by condensation of 4-amino-benzo-15-crown-5 with succinic anhydride or maleic anhydride, respectively. In order to increase the solubility of the amides I and II in water and to improve their efficiency as food stabilizers, the complexes with potassium 2-propenyl-acrylate (Ia and IIa) were prepared. Potassium 2-propenyl-acrylate is a well known fungistatic agent widely used as food stabilizer under the name of sorbic acid (THE MERCK INDEX, 1976). An attempt to prepare benzo-15-crown-5-phthalic acid was unsuccessful since melting of the equimolar mixture of amino-benzo- 15 -crown- 5 with phthalic anhydride leads to the loss of water and ammonia under the formation of ester-diamide III. Complexes IVa and IVb are under investigation in our Laboratory as potential browning inhibitors of cut fruits and fruit juices (ŠUBARIĆ \& Piližota, 1998). 


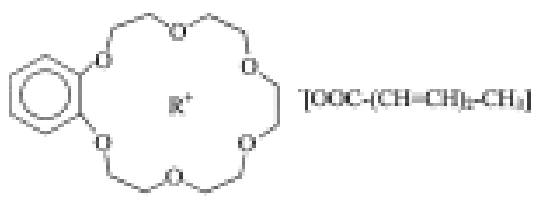

$\mathrm{TVa} \mathrm{R}-\mathrm{H}$

IVb $\mathbb{R}=\mathrm{K}$

\section{Conclusions}

Addition of 4'-N(aminobenzo-15-crown-5) to succinic anhydride and maleic anhydride gave the corresponding amides: 4'N(benzo-15-crown-5) succinamic acid (I) and 4'-N(benzo-15-crown-5)maleamic acid (II). The reaction of amino benzo-15crown-5 with phthalic anhydride gave the ester of 4'-(benzo-15-crown-5)-bis[4'$\mathrm{N}$ (benzo-15-crown-5)]phthalamic acid (III). Crown compounds I and II gave complexes with potassium 2-propenyl-acrylates (Ia and IIa). One to one complexes were formed by mixing benzo-18-crown-6 with 2-propenyl acrylic acid and potassium 2-propenyl-acrylate. The compounds I to III and complexes Ia, IIa and IVa and b were prepared as potential inhibitors of enzymatic discolouration of food.

This paper was supported by the Ministry of Science and Technology of Croatia, and the U.S Department of Agriculture (USDA)

\section{References}

BURNS, J. J. \& GREENBERG, D. M. (1963): Metabolic pathways, Vol. 1., Academic Press Inc., New York, p. 341 (Review article); cit. from: KIRK-OTHMER, Encyclopedia of chemical technology. John Wiley and Sons Inc., 2nd ed., Vol 2, pp. 747-762.

Fleš, D. D., GOlJA, G., HACE, D., VuKOVIC, R. \& FLĚ̆, D. (1994): The extraction of sodium and potassium picrates with poly(benzo-15-crown-5)maleimide, poly(benzo-15-crown-5)maleimide-alt$\alpha$-methylstyrene and benzo-15-crown-5. Polym. Bull., 33, 425-430.

FLEŠ, D. D., HACE, D., RANOGAJEC, F. \& VUKOVIC, R (1992): Copolymerization of $\alpha$-methylstyrene with 4'-N(benzo-15-crown-5)maleimide. Polym. Bull., 29, 153-157.

HICKS, K. B., HAINES, R. M., TONG, C. B. S., SAPERS, G. M., El-ATAwY, Y., IRwiN, P. L. \& SEIB, P. A. (1996): Inhibition of enzymatic browning in fresh fruit and vegetable juices by soluble and insoluble forms of $\beta$-cyclodextrin alone or in combination with phosphates. J. agric. Fd Chem., 44 (9), 2591-2594. 
HIRAOKA, H. (1982): Crown compounds, their characteristics and applications. -in: Studies in organic chemistry. Kodansha Ltd., Tokyo and Elsevier Scientific Publ. Co., Amsterdam, p. 75.

THE MERCK INDEX (1976): An encyclopedia of chemicals and drugs. Publ. Merck and Co., Inc. Rahway, N. J. Compound number 8495: sorbic acid

Pedersen, C. J. (1967a): Cyclic polyethers and their complexes with metal salts. J. Am. chem. Soc., 89, $2495-2496$

PEDERSEN, C. J. (1967b): Cyclic polyethers and their complexes with metal salts, J. Am. chem. Soc., 89, $7017-7036$

PEDERSEN, C. J. (1970a): Crystalline salt complexes of macrocyclic polyethers, J. Am. chem. Soc., 92, 386-391.

PEDERSEN, C. J. (1970b): New macrocyclic polyethers, J. Am. chem. Soc., 92, 391-394.

PEDERSEN, C. J. \& FRENDSDORFF, H. K. (1972): Macrocyclic polyethers and their complexes. Angew. Chem. Intern. Ed., 11, 16-25.

PILIŽOTA, V. (1998): Application of polymeric materials as selective supports in chromatography. (Review article). Kem. Ind., 47(3), 93-101.

PILIŽOtA, V. \& ŠUBARIĆ, D. (1998): Control of enzymatic browning of foods. (Review article). Fd Technol. Biotechnol., 36 (3) 219-227.

POONIA, N. S. (1974): Coordination chemistry of sodium and potassium complexation with macrocyclic polyethers. J. Am. chem. Soc., 96, 1012-1019.

SAPERS, G. M. (1993): Scientific status summary, Browning of foods: Control by sulfites, antioxidants and other means. Fd Technol., 10, 75-84.

ŠUBARIC, D. \& PILIŽOTA, V. (1998): Unpublished results from our laboratories.

VÁMOS-VIGYÁZÓ, L. (1981): Polyphenol oxidase and peroxidase in fruit and vegetables. CRC crit. Rev. Fd Sci. Nutr., 15, 49-127. 